\title{
3-D numerical simulation of influence of twin pile group loadings on neighboring railway subgrade
}

\author{
Dong Xiao ${ }^{1, \text { a }}$, Guanlu Jiang ${ }^{1, b}$, Fangdong Gao $^{1}$ \\ ${ }^{1}$ School of Civil Engineering, Southwest Jiaotong University, Chengdu 610031, China \\ aemail: hxxding@sina.cn, bemail: wgljiang@google.com
}

Keywords: Twin Pile Groups; Subgrade; Numerical Analysis; Interaction

\begin{abstract}
In order to investigate the effect of twin pile group loadings on nearby existing railway subgrade, elastic plastic model was established by adopting finite differential method based on a practical case. It is proved by comparison with field monitoring data that the numerical analysis of the influence due to twin pile group loadings on neighboring railway subgrade is reliable. The results indicate that both horizontal displacement and settlement of subgrade decrease with the increase of pile length, but both of them are insignificantly affected. Owing to superposition effect of twin pile group loading located symmetrically on both sides of subgrade, uneven additional settlement of subgrade can be mitigated, while the maximum vertical deformation is more pronounced.
\end{abstract}

\section{Introduction}

In recent years, with the rapid development of China's transportation industry, such as expressway and high-speed railway construction, numerous projects for crossover lines continuously emerge. To realize the bridge swivel docking, it is inevitable to construct newly bridge pile foundation closely to the existing highway, so that additional displacement and stress in surrounding soils occur, which leads to tilt and deformation of nearby subgrade. When its value exceeds a certain range, it will endanger safe operation and normal function of railway.

In order to understand the internal force and deformation caused by twin pile groups, scholars at home and abroad have made numerous studies on relative contents. Schroeder et al [1] and Yan et al [2] implored the effect of pile group loading on adjacent tunnel, including stress and deformation by finite element method. Furthermore, Schroeder [3] investigated systematically various aspects about the influence of pile loading on tunnels, such as tunnel's distortion and overall displacement with varies of arrangement of piles, pile center-to-center distance and pile-tunnel net offset. Lou [4] and $\mathrm{Li}$ et al. [5] also analyzed the influence of the pile foundation and deep pile foundation on the adjacent metro tunnel. However, most of the studies are aimed at the tunnels or other structures or services. There is little research available about the impact on railway subgrades.

Based on the literature [6], this paper focuses on deformation response against existing subgrade by twin pile groups through the 3-D numerical simulation. Firstly, 3-D elastic plastic numerical model was established where the results obtained from the model agreed well with field measurements. Then, mechanism of interaction between the pile group and subgrade was investigated. Finally, the efficacy of protective measure utilized in practical engineering was evaluated.

\section{Practical engineering}

Newly Chengdu second ring expressway perpendicularly overpasses the existing Cheng-guan high speed railway. The superstructure of expressway consists of $2 \times 75 \mathrm{~m}$ pre-stressed concrete single T-type rigid frame continuous beams. With the full scaffold construction method, cross swivel closure occurred when the beam concreting is finished. The angles of left and right line of the expressway versus the railway line are $59^{\circ}$ and $58^{\circ}$, respectively. Bored pile foundation was adopted for bridge foundation of expressway with pile length $30 \mathrm{~m}$, pile diameter $1.5 \mathrm{~m}$, pile 
numbers 12 and circular symmetrical arrangement. The pile cap has a radius of $8 \mathrm{~m}$, a height of $7 \mathrm{~m}$, and depth below the ground surface $3 \mathrm{~m}$. The net spacing between pile cap and subgrade is mere $11 \mathrm{~m}$. To isolate adverse influence, such as additional deformation and mechanical interaction, induced by twin pile group loadings on nearby high speed railway, micro-piles with cast-in-place, embedded between the pile cap and railway subgrade, was employed as protective measure. The construction process and parameters and field monitoring layout refer to the literature [6] [7]. The relative position and detail size of bridge foundation and subgrade are illustrated in Fig.1.

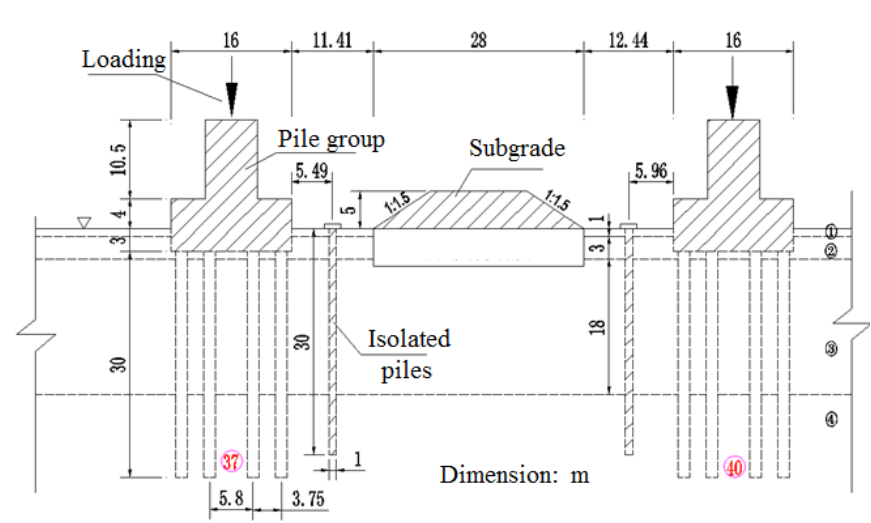

(a) Cross section view

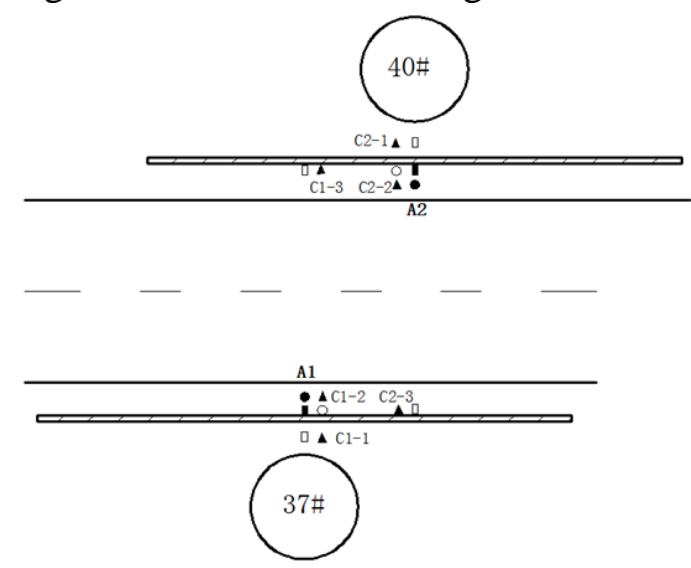

(b) Plain view

Fig.1 Relative location and measurement layout

At present, the semi-theoretical and semi-empirical design methods are still widely adopted in practical engineering of pile groups, such as the equivalent solid pier method commonly used in specification [8] and Mindlin stress formula based on elastic half space theory [9]. According to these methods, the influence generated by pile groups on surrounding soils and nearby structures is able to quantify. Because loading exerts only once, these methods can't comprehensively reflect complex situation of practical projects. Therefore, three-dimensional elastic plastic difference model considering multi-stage loading was employed to model the construction process of bridge pile foundation, so that the safety of railway subgrade can be guaranteed at every stage of pile group loading.

\section{3-D numerical simulation}

In numerical calculation, Mohr-Coulomb model is chosen to simulate the basic physical and mechanical properties of soil and composite foundation, which obeys the Mohr-Coulomb shear failure. Pile cap and pier are modelled by solid element, while pile shaft is simulated by pile unit. In the modelling process, the interface of pile-soil is modelled as contact element for simulating actual contact effect, owing to big difference of stiffness and water impermeability. In addition, the coupling analysis is adopted to simulate the influence of groundwater, and the whole modelling process consists of 2 calculation models: static and seepage. For seepage calculation, the bottom of the model is set the impervious boundary, while the vertical boundary of the model allows the horizontal seepage flow. For static calculation, the boundary of the model is set to the rolling bearing, while the bottom is fixed with the fixed support. The physical and mechanical properties of the soil used in calculation are shown in Table 1.

Table1 Soil properties in calculation

\begin{tabular}{|c|c|c|c|c|c|c|}
\hline Soil type & $\begin{array}{c}\text { Unit weight } \\
/ \mathrm{kNm}^{-3}\end{array}$ & $\begin{array}{c}\text { Compression } \\
\text { modulus/MPa }\end{array}$ & $\begin{array}{c}\text { Poisson's } \\
\text { ratio }\end{array}$ & $\begin{array}{c}\text { Cohesion/ } \\
\mathrm{kPa}\end{array}$ & $\begin{array}{c}\text { Internal fraction } \\
\text { angel/ }\left({ }^{\circ}\right)\end{array}$ & $\begin{array}{c}\text { Permeability } \\
\text { coefficient } / \mathrm{cm}^{-1}\end{array}$ \\
\hline Silty clay & 18.4 & 4.3 & 0.35 & 10 & 9 & $3.2 \times 10-5$ \\
\hline $\begin{array}{c}\text { Slightly } \\
\text { dense sand }\end{array}$ & 20.3 & 33.6 & 0.3 & 0 & 38 & 0.5 \\
\hline $\begin{array}{c}\text { Medium } \\
\text { dense sand }\end{array}$ & 21.4 & 50 & 0.25 & 0 & 45 & 0.2 \\
\hline Dense sand & 21.4 & 60 & 0.25 & 0 & 45 & 0.1 \\
\hline
\end{tabular}


The procedure of addressing the issue can be described as follows: (1) embedding micro isolated steel pile wall; (2) constructing the pile group; (3) concreting the bridge pier; (4) concreting the T-type rigid beam. In every stages, the pore pressure of groundwater is taken into account. The model mesh was established as shown in Fig.2.

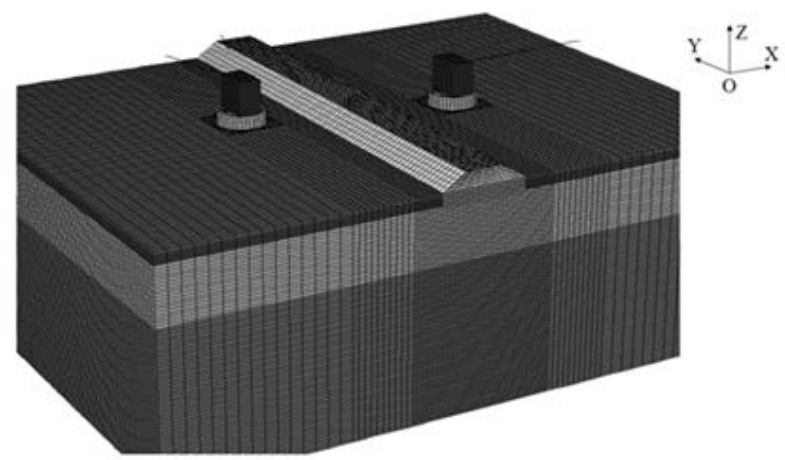

Fig.2 Three-dimensional numerical model

\section{Results and comparison}

Firstly, this section aims to compare the computed results with the measured data, so that the results calculated from numerical simulation is able to be verified. Fig.3 illustrated that horizontal displacement at various field points versus depth over different stages. It is demonstrated that horizontal displacement of subgrade induced by twin pile groups varies from negative value (toward pile group) to positive one (outward pile group) with depth, where the neutral point occurs at the depth $11 \mathrm{~m}$. Furthermore, maximum value of horizontal displacement tends to increase with the magnitude of pile group loading. Most importantly, favorable agreement between the calculated results with field measurements has achieved to verify the reasonability of the numerical model in Fig.3.

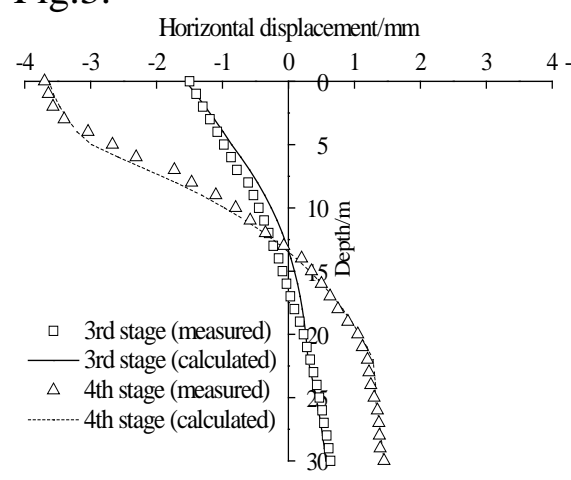

(a) $\mathrm{C} 1-1$

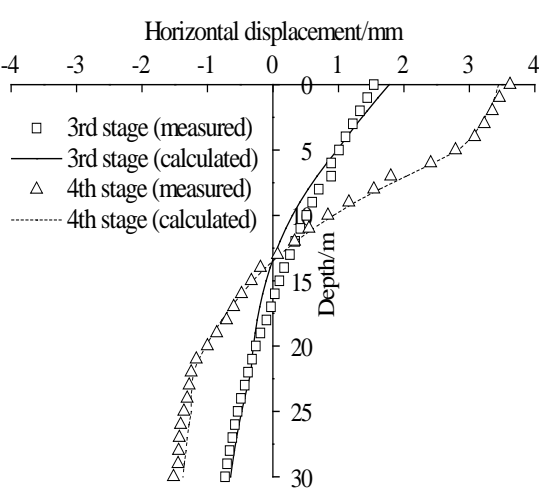

(b) $\mathrm{C} 2-1$

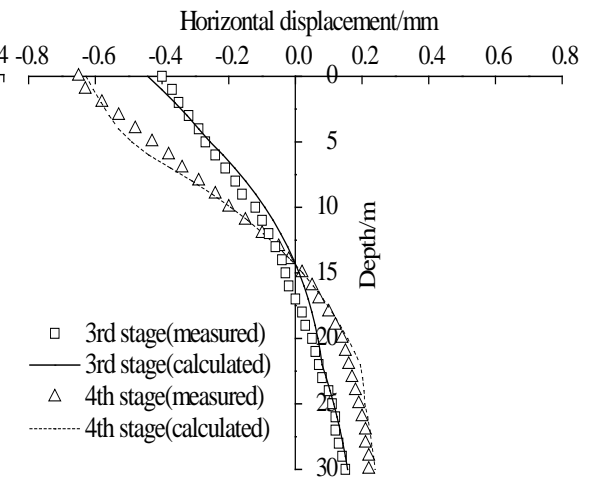

(c) A1-diaphragm wall

Fig.3 Horizontal displacements of C1-1、C2-1 and diaphragm wall at section A1

Considering responses of subgrade resulting from interaction between the twin pile group loading, it is necessary to identify the way in which interaction occurs. There is a chance to analyze and address the problem in which additional settlement of subgrade generated by single pile group and twin pile groups are calculated respectively so as to compare with each other, as illustrated in Fig.4. In comparison, well agreement of the curves can show that the additional deformation induced by twin pile groups exhibits the superposition of singe ones does. One the other hand, Fig. 4 also clearly shows that owing to superposition effect of twin pile group loading located symmetrically on both sides of subgrade, uneven additional settlement of subgrade can be mitigated, while the maximum vertical deformation is more pronounced. 


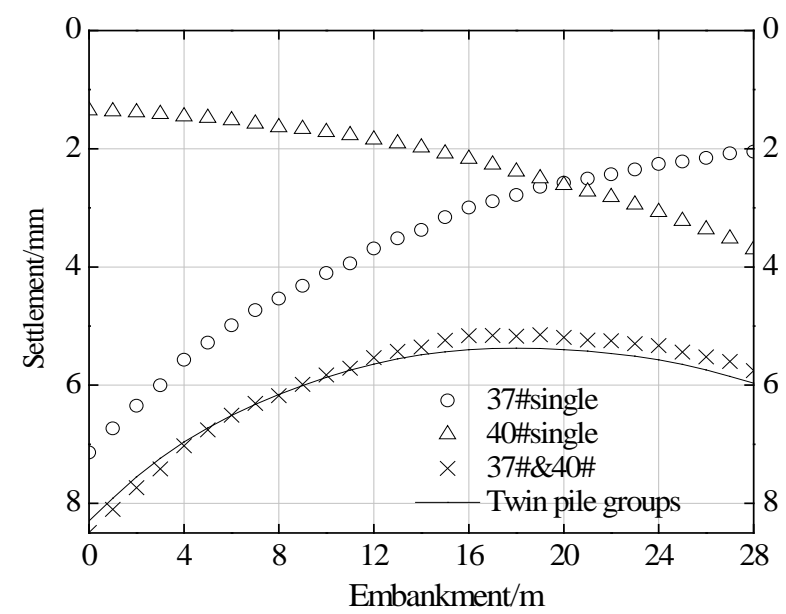

Fig. 4 Subgrade settlements at different conditions

In order to investigate the effect of geometry of micro isolated steel pile wall on mitigation of influence, especially its length, a plot for deformation of subgrade versus the pile length is illustrated in Fig.5. Fig.5 (a) shows with the increase of pile length from 0.8 to 1.2 times, the settlement of subgrade decrease obviously, in which the maximum settlement of subgrade ranges from $9.5 \mathrm{~mm}$ to $7.7 \mathrm{~mm}$. Fig.5 (b) illustrates that horizontal displacement of subgrade at the ground surface also is significantly mitigated from $4 \mathrm{~mm}$ to $1.5 \mathrm{~mm}$ in maximum values, even though the magnitude of the decrease is not obvious. In general, the pile length is a sensitive factor to design the actual practice.

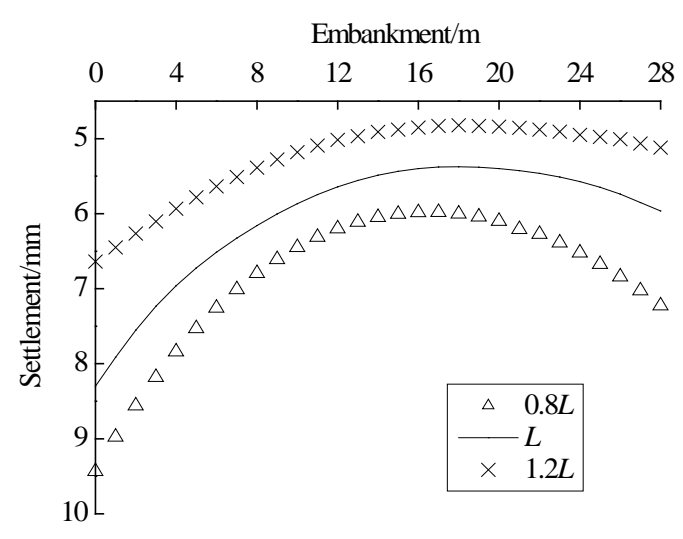

(a) Settlement

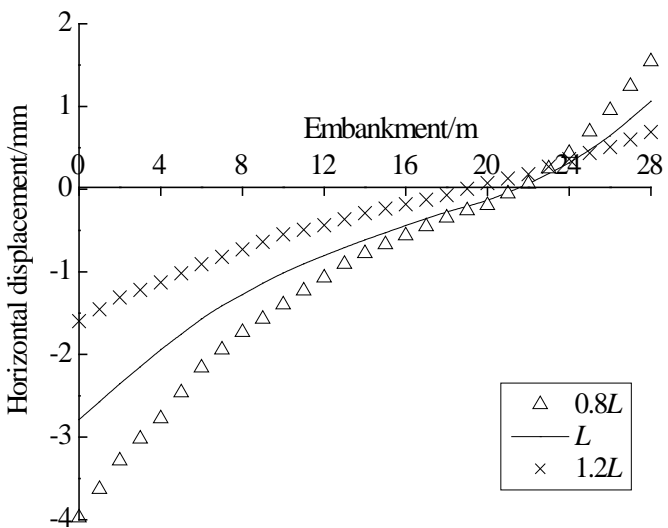

(b) Horizontal displacement

Fig.5 The influence of micro pile length on the deformation of subgrade

\section{Conclusion}

(1) The comparison between the calculated and measured results of subgrade's deformation generated by twin pile group loadings verifies the reliability of the numerical model established based on the finite difference method;

(2) Mechanism of influence of twin pile group loadings on the existing subgrade consists of the following 3 parts: (1) with change of additional stress and strain due to pile group loadings, the settlement and horizontal displacement of subgrade increase; (2) the subgrade deformation induced by interaction of twin pile groups can be regard as the superposition effect of single one; (3) horizontal displacement of subgrade induced by twin pile groups varies from negative value to positive one with depth, where the neutral point occurs at the depth $11 \mathrm{~m}$.

(3) Based on parameter analysis, the horizontal displacement and settlement of subgrade increases with the pile length, but the magnitude of decrease is not obvious. Owing to superposition effect of twin pile group loading located symmetrically on both sides of subgrade, uneven additional settlement of subgrade can be mitigated, while the maximum vertical deformation is more pronounced. 


\section{Acknowledgement}

In this paper, the research was sponsored by Project (Z2012-061) supported by the Science and Technology Department of Railway Ministry.

\section{References}

[1] Schroeder F C. The influence of pile group loading on existing tunnels [J]. Géotechnique, 2004, 54(54):351-362.

[2] Yan Jing-ya, Zhang Zi-xin, Huang Hong-wei. Finite element analysis of influence of pile group loading on existing neighboring tunnels [J]. Rock and Soil Mechanics, 2008, 29(9): 2508-2514.

[3] Schroeder F C. The influence of bored piles on existing tunnels [D]. Imperial College London (University of London), 2003.

[4] Lou Xiao-ming, Jin Zhi-jing. Analysis of the influence of bored pile foundation on adjacent metro Tunnels [J] .Rock and Soil Mechanics, 1996, 17(3): 48-53.

[5] Li Jing-pei, Wang Kun. Influence of extra-deep pile groups on existing neighboring tunnels [J].Chinese Journal of Geotechnical Engineering, 2011, 33 (supp.2):129-134.

[6] Jiang Guan-lu, Pang Mei, Xiao Dong, et al. Additional effects on high-speed railway subgrade caused by a newly-built flyover and treatment techniques [J]. China Railway Science, 2013, 34(5): 6-14.

[7] Pan Wei. Field test analysis and processing effect assessment on the influence of construction load of T-pattern bridge on high speed railway subgrade[D].Southwest Jiaotong University, 2014.

[8]JTGD63-2007 Code for design of ground base and foundation of highway bridges and culverts [S]. Beijing: China Communications Press, 2007.

[9] Mindlin R. D. Force at a point in the interior of a semi-infinite solid[J]. Physics, 1936, 7(5): 195-202. 